\title{
Corrigendum \\ Corrigendum to "Empirical Reduced-Order Modeling for Boundary Feedback Flow Control”
}

\author{
Seddik M. Djouadi, ${ }^{1}$ R. Chris Camphouse, ${ }^{2}$ and James H. Myatt ${ }^{3}$ \\ ${ }^{1}$ Department of Electrical Engineering and Computer Science, University of Tennessee, 1508 Middle Drive, \\ Knoxville, TN 37996, USA \\ ${ }^{2}$ Performance Assessment and Decision Analysis Department, Carlsbad Program Group, Sandia National Laboratories, \\ 4100 National Parks Highway MS 1395, Carlsbad, NM 88220, USA \\ ${ }^{3}$ Air Force Research Laboratory, Wright-Patterson Air Force Base, Dayton, OH 45433, USA \\ Correspondence should be addressed to Seddik M. Djouadi; djouadi@eecs.utk.edu
}

Received 7 March 2017; Accepted 28 March 2017; Published 19 September 2017

Copyright ( 2017 Seddik M. Djouadi et al. This is an open access article distributed under the Creative Commons Attribution License, which permits unrestricted use, distribution, and reproduction in any medium, provided the original work is properly cited.

The article titled "Empirical Reduced-Order Modeling for Boundary Feedback Flow Control" [1] was found to contain material from the following published article: Seddik M. Djouadi, R. C. Camphouse, J. H. Myatt: Reduced order models for boundary feedback flow control. American Control Conference, 2008. 11-13 June 2008. Date Added to IEEE Xplore: 05 August 2008. DOI: 10.1109/ACC.2008.4587119.

This was not cited due to an oversight. The JCSE article expands on the ACC 08 publication by $30 \%$, including a new section on controller design. In Section 2, Problem Geometry, the authors added several expressions (18) to (22), with explanations. The Introduction is organized differently and contains a paragraph addressing the issue of closed loop model reduction. There are more explanations and Figure 9 in Section 6, Controller Design. In Section 5, Application to the Galerkin Model, the authors added more explanation with expressions (61) and (63).

\section{References}

[1] S. M. Djouadi, R. C. Camphouse, and J. H. Myatt, "Empirical reduced-order modeling for boundary feedback flow control," Journal of Control Science and Engineering, vol. 2008, Article ID 154956, 11 pages, 2008. 


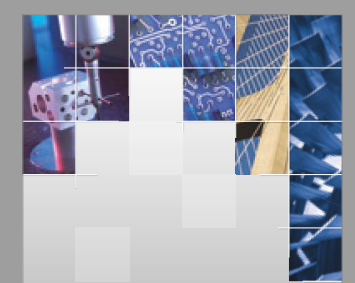

\section{Enfincering}


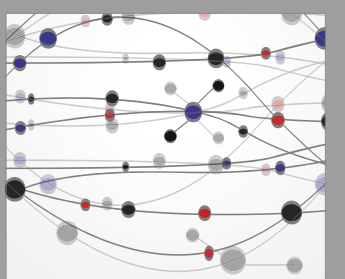

The Scientific World Journal

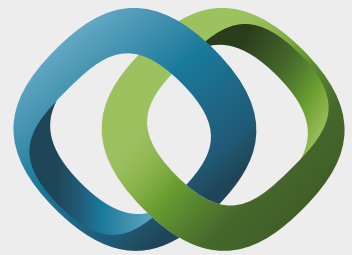

\section{Hindawi}

Submit your manuscripts at

https://www.hindawi.com


\section{Rotating}

Machinery
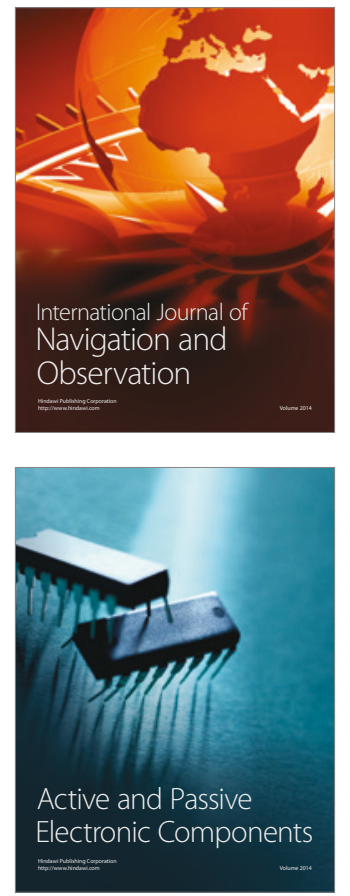
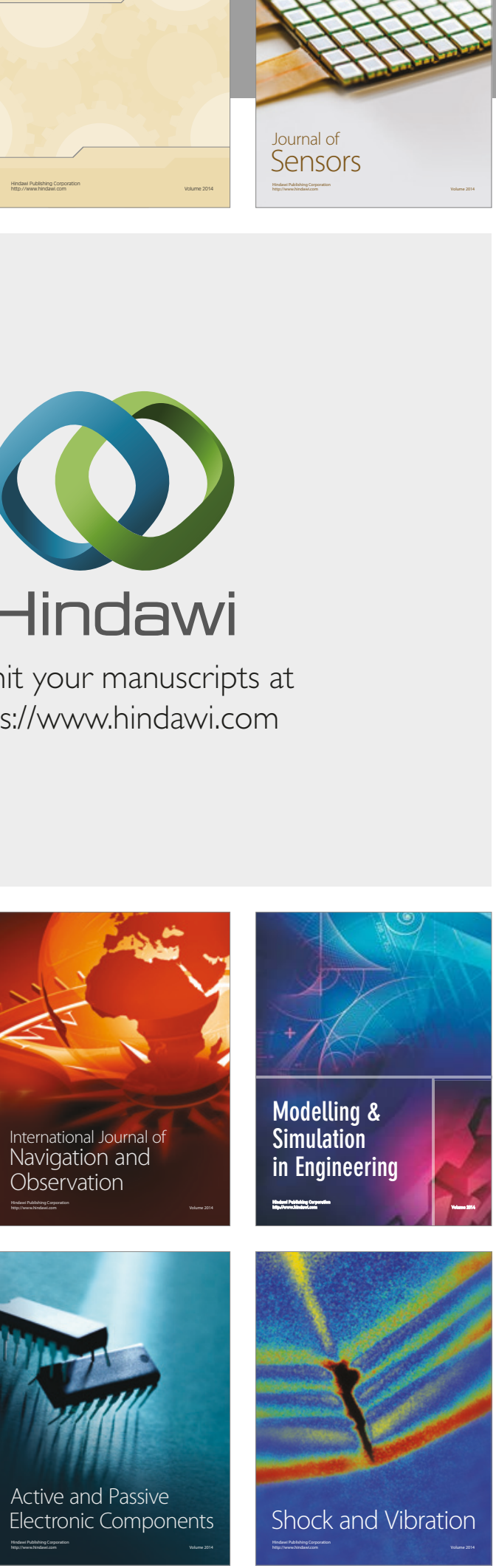
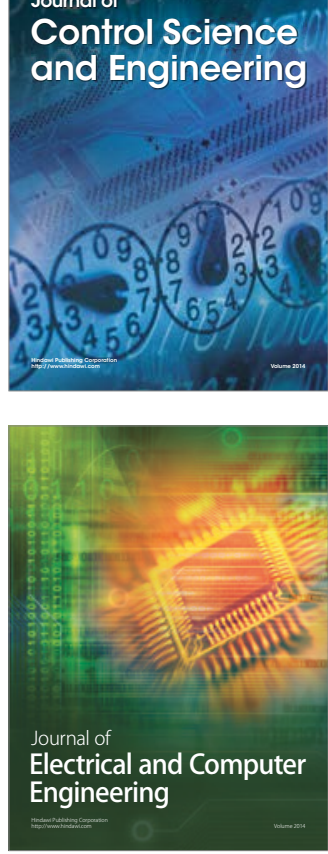

Distributed

Journal of

Control Science

and Engineering
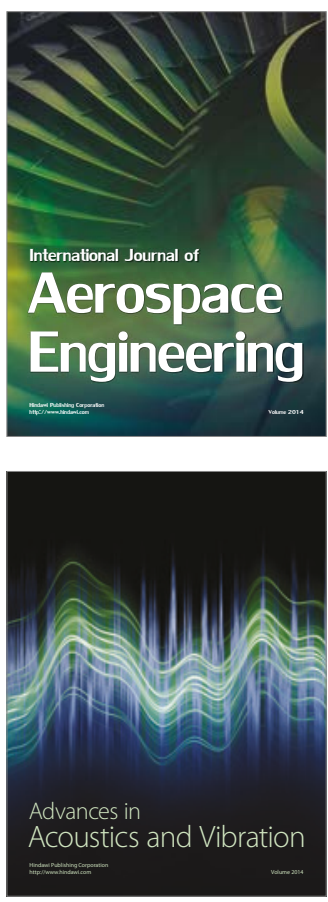

Sensor Networks 